\title{
High Accuracy Geodetic Control Point Measurement Using GPS Geodetic With Static Methods
}

\author{
Eko Nugroho Julianto $^{1, \text { a) }}$, Ispen Safrel ${ }^{1, \text { b) }}$, Arie Taveriyanto ${ }^{1}$ \\ ${ }^{1}$ Department of Civil Engineering, Faculty of Engineering, Universitas Negeri Semarang \\ a) Corresponding author: en.julianto@mail.unnes.ac.id \\ b) Ispen.Safrel@yahoo.com
}

\begin{abstract}
The quality of the coordinates of the points in a generally horizontal control network will be influenced by many factors, such as the system equipment used for measuring / observation, the network geometry, measurement strategies / observation, as well as data processing strategy implemented. Using development of the GPS satellite system, since 1989, the network provision of horizontal control points in Indonesia generally relies on the GPS satellite observations. One way of measuring geodetic control points with high accuracy is using geodetic GPS. Measurement of geodetic control points required as a control in the execution of the work and as a correction coordinate measurement of the position of a measurement object with a high degree of accuracy $( \pm 1 \mathrm{~cm})$. How many measurement methods that can be done. This research conducted measurement using static method. Static surveys are used to determine the coordinates of the control points are relatively distant from each other as well as order accuracy requires relatively higher. The measurement results obtained coordinate data for point 1 is $6^{\circ} 57$ ' 31.92207 "LS; $109^{\circ} 38^{\prime} 32.25194$ "BT; high (ellipsoid) $34320 \mathrm{~m}$ and point 2 is $6^{\circ} 57$ ' 33.59086 "LS; $109^{\circ} 38^{\prime}$ ' 37.87710 "BT; high (ellipsoid) $36235 \mathrm{~m}$.
\end{abstract}

Keywords: geodetic control points, geodetic GPS, high accuracy, static method.

\section{INTRODUCTION}

Act on Geospatial Information in chapter 1 verse 8 says that the geodetic control points are positions in the face of the earth that is characterized by certain physical shape is used as a frame of reference for the position of Geospatial Information [1]. Positioning point on the earth's surface can be done with 2 ways, terrestrial and extra-terrestrial. The method of determining the position of a point by means of terrestrial is done based on measurements and observations of the earth. While the method of extra-terrestrial, positioning is performed by measurement or observation to the object / celestial bodies, whether natural (such as the moon, stars and squar) and man-made such as satellites.

In the development of extra-terrestrial survey, the use of GPS surveys are often used to determine the geodetic control points, both horizontal control points and vertical control points, where to take measurements control framework is not independent of geodetic network. Geodetic network can also be defined as a form of geometry that consists of three or more points geodetic measurements, which measurement consists of a horizontal distance measurement, the azimuth angle, etc. [2].

Making the web design on a geodetic GPS surveying influence on activities in the field of measurement, such as the time and cost required. Besides the quality of the coordinates of the points in a network obtained by GPS surveys, it will depend on the quality of a geometry network used. Design of the geometry network is useful for planning the 
level of accuracy obtained before any measurement is made. The design geometry quality network can also eliminate errors [3].

The benchmark is a point whose position is known with a high degree of accuracy and are usually marked in some way. There are two types of benchmarks, ie "vertical control points" were marked by very precise elevation above the standard datum field (that is elevation "above sea level") and "horizontal control points" which sets the latitude and longitude of a location.

Benchmark has a classification of accuracy called order. Order is an attribute that indicates the external accuracy of a network as a network-class functions, proximity of the data measurement of the network which is used for bonding and precision of data transformation process. In accordance with Article 1, point 13 PP 24/1997 on benchmark point [4] as follows:

1. Order point 0 and 1 are the national basic framework points gained and regulated by Bakosurtanal

2. Order point 2 (density $+10 \mathrm{~km}$ ) attached to the Order point 0 and 1

3. Order point 3 (density $+1-2 \mathrm{~km}$ ) attached to the Order point 2

4. Order point 4 (density $+150 \mathrm{~m}$ ) attached to the Order point 3

\section{GPS AND GPS GEODETIC}

GNSS (Global Navigation Satellite System) is a satellite system that consists of a constellation of satellites that provide information about the time and location, exuding all kinds of rays in various frequencies on an ongoing basis, which is available at all locations on the surface of the earth. GNSS has an important role in navigation. Existing GNSS is a GPS (Global Positioning System), which is owned and managed by the United States, GLONASS (Global Navigation Satellite System) belonging to Russia, belonging to the EU Galileo, and Compass or Beidou belong to China. India and Japan have developed regional GNSS capability by launching a satellite into space to add capabilities that are provided by a global system to provide additional regional coverage [5].

GNSS most known today is the GPS (Global Positioning System). The system is designed to give a threedimensional position and velocity as well as information about the time, continuously throughout the world without depending on time and weather, to many people simultaneously. At this time, the GPS system has been very widely used around the world in various fields of application. In Indonesia too, the GPS has been widely applied, especially associated with demanding applications or change information about the position of posisi.GPS is a radio navigation system and positioning using satellites [6]. The system was developed by the US Defense Department.

Compared to systems and methods for positioning, GPS has many advantages and offers many advantages, both in terms of its operation and the quality of a given position. Basically GPS consists of three main segments, the space segment (space segment), which is mainly composed of GPS satellites, the segment control system (control system segment) consisting of stations monitors and controls the satellite, and segment user (user segment ) which consists of the user GPS receiver including tools and signal processor and GPS data. The third segment is depicted schematically in Figure 2.1. [3]

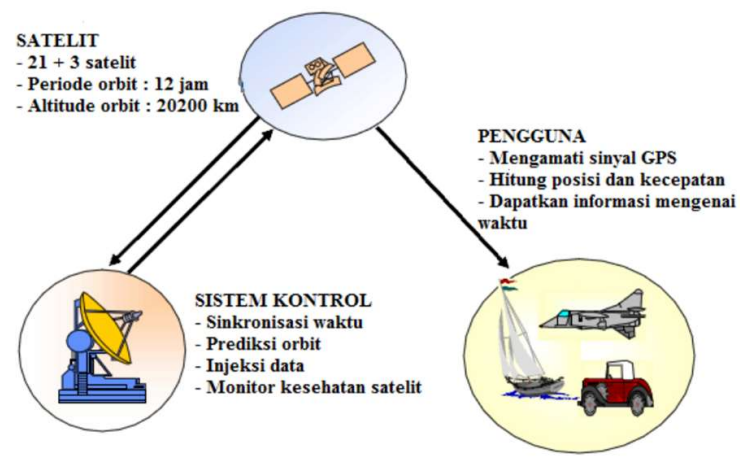

FIGURE 1. Global Positioning System, GPS

Geodetic GPS is a GPS device that has a high scale used for the purposes of the survey. Geodetic GPS has a sufficiently high measurement accuracy. Position accuracy obtained with GPS observations will depend on four 
factors: 1) Assisted positioning methods used, 2) satellite geometry, 3) The accuracy of the data used, and 4) applied method strategy. GPS Geodetic used in this measurement is type of Hemisphere GPS Geodetic S320.

\section{POSITIONING WITH GPS}

The basic concept of GPS positioning is resection (binding to the rear) with a distance, which is the simultaneous measurement of the distance to a number of GPS satellites known coordinates. In the vector, the basic principle of GPS positioning is shown in the figure below. In this case, the parameters to be determined is the geocentric position vector observer (R). Therefore, because the GPS satellite geocentric position vector $(r)$ are known, then something to be determined is the vector position of the satellite to the observer toposentric $(\rho)$.

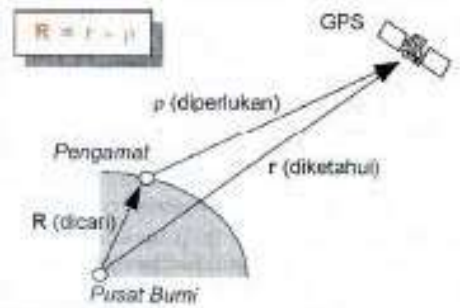

FIGURE 2. Basic Principles of Positioning With GPS (Vector Approach)

The position given by the GPS is a three-dimensional position (X, Y, Z or $\varphi, \lambda, \mathrm{h}$ ) expressed in WGS-84. With GPS, the specified point position can be stationary (static positioning) or moving (kinematic positioning). Position point can be determined using a GPS receiver to the center of the earth by using absolute positioning method, or to other points of known coordinates (reference stations) by using the differential method (relative) who use at least two GPS receivers. GPS can also provide instant position (real time) or after observation of data more extensively processed (post procesing) is usually done to get a better accuracy.

\section{STATIC MEASUREMENT METHOD}

Static positioning method (static position) is the positioning of the points that static (stationary). Positioning can be performed in absolute or differential, using data pseudorange and phase, as shown in the following figure.

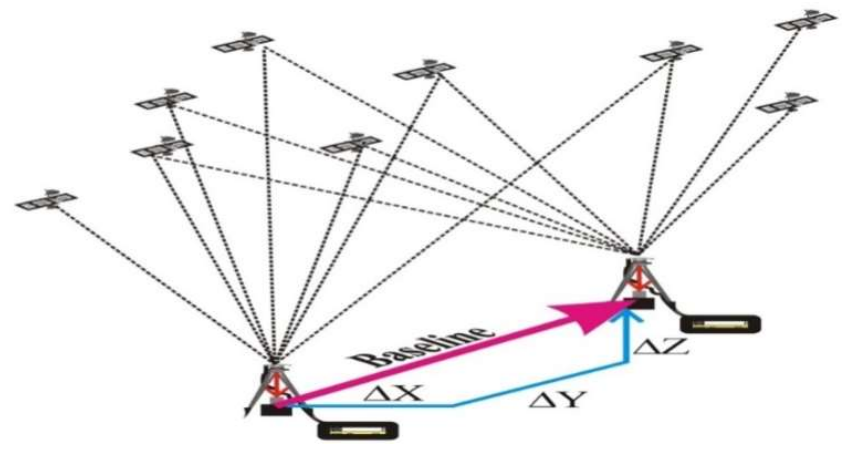

FIGURE 3. Measurement Method with Static

When compared with Kinematic positioning, measurement with static methods position accuracy obtained is generally relatively high (can reach the order of $\mathrm{mm}$ to $\mathrm{cm}$ ). One form of implementation of static positioning methods is the GPS survey to determine the coordinates of the control points for mapping purposes.

Measurements using static method requires two receivers, both made a point of reference (base). In one set of GPS equipment, there are 2 types of receivers that BASE and ROVER, but at this time GPS observations Rover is set into the base. 


\section{METHODOLOGY}

\section{Measurement methods}

In order to determine a fixed point or Bench Mark surface of the earth, first determine the points to be measured. The fixed point or Bench Mark is intended as a reference for the measurement of other measurements related to coordinate. There are many methods that can be used to determine a fixed point, in this study the method used is the method of determining a static position.

\section{Measurement Location}

Measurement of geodetic control points with high accuracy are conducted in SMK 1 Kedungwuni Pekalongan. The location was choosen because it has curriculum of geomatics competence and as a form of institutional cooperation between research institutions with schools as partner in helping to provide learning media and training in the use of geodetic GPS equipment.

\section{Tools and Materials}

In general, the equipment needed in the observation process the data for a GPS survey for the purposes of surveying and mapping will include:

1. GPS receiver and antenna following ancillary equipment.

2. Motor vehicle to facilitate the movement of the tools and personel from point to point.

3. Hint time.

4. Charger (battery charger).

Of equipment above, the most important is a GPS receiver. In detail, the GPS receiver and complementary equipment used as image below [7].

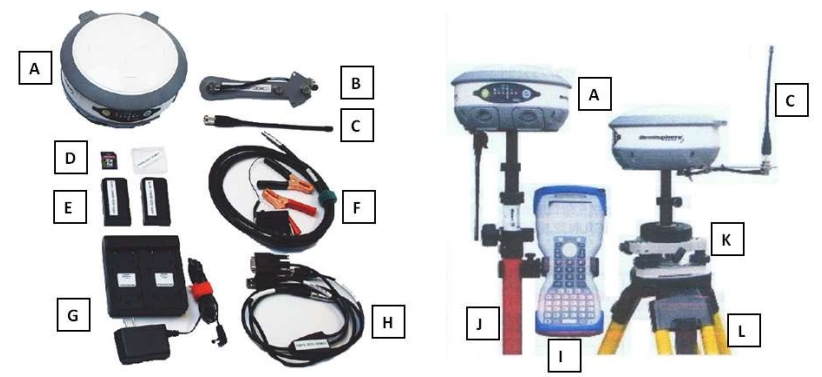

FIGURE 4. Geodetic GPS Tools

TABLE 1. Geodetic GPS Tools

\begin{tabular}{|c|c|c|c|}
\hline item & Equipment & $\begin{array}{c}\text { Number of } \\
\text { units }\end{array}$ & Information \\
\hline $\mathbf{A}$ & receiver S320 & 2 unit & $\begin{array}{l}\text { Sn: B1232-S3204M-1862576A } \\
\text { Sn: B1232-S3204M-1862579A }\end{array}$ \\
\hline B & Radio Antenna Bracket & 2 unit & PN: 602-1096-000 \\
\hline $\mathbf{C}$ & Antennas UHF Radio & 2 unit & PN: $150-0043-000$ \\
\hline D & SD Card & 2 unit & PN: 750-1099-000 \\
\hline $\mathbf{E}$ & Batteries (rechargeable lithium-ion) & 4 units & PN: 427-0043-000 \\
\hline $\mathbf{F}$ & $\begin{array}{l}\text { Power cable, external, 2-pin circular, } 3 \mathrm{~m} \text { (for base } \\
\text { station unit) }\end{array}$ & 1 unit & pn; 054-0119-000 \\
\hline G & Battery Charger + Power Adapter & 2 sets & $\begin{array}{l}\text { Pn Adapter: S1133094854 } \\
\text { Pn Adapter: S1133094841 }\end{array}$ \\
\hline $\mathbf{H}$ & $\begin{array}{l}\text { Data Cable, 9-pin to 9-pin serial, USB Connector and } \\
\text { USB Receptacle }\end{array}$ & 1 pair & PN: 051-0258-000 \\
\hline
\end{tabular}




\begin{tabular}{llcc}
\hline $\mathbf{I}$ & Controller CarlsonSurveyor + & 1 unit & Pn: P23201075A1 \\
\hline $\mathbf{J}$ & Adjustable GPS Rover Pole & 1 unit & \\
\hline $\mathbf{K}$ & Tribrach and Adapters & 1 set & \\
\hline $\mathbf{L}$ & tripod & 1 unit & \\
\hline & Pole Mount and GPS Cradle & 1 pair & Pn: TC-8-3 and TC-8-4 \\
\hline & Meter (3m) to measure the height of the antenna & 1 unit & PN: 699-0004-000 \\
\hline & Hard Case (Tool Box) & 1 unit & \\
\hline
\end{tabular}

\section{Measurement}

Stages geodetic measurements using GPS equipment with static methods is divided into several stages, while the stages are:

1. GPS receiver equipment settings Base until ready to use.

2. Turning Controller and running the Carlson Survey program and creating new task.

3. Settings the Configuration reciver Base I.

4. Settings the Configuration reciver Base II.

5. Conduct a positioning survey.

6. Export and Download Data observations.

7. Ending the measurement by turning off the Controller and turn off equipment.

\section{Data processing}

In geodetic GPS measurements using static methods, there are some supporting software for measurement data processing. To obtain good measurement results it is necessary rigor in data collection and data processing time. Here are some applications that are used for data processing static measurement results: TTC (Trimble Total Control), tuberculosis (Trimble Bussines Center), Topcon Tools, and GAMMIT. But in this study, the data processing using a TBC (Trimble Bussines Center)[8]. TBC (Trimble Bussines Center) is a software / software to process the data postprocessing, network analysis and grading issued by one firm Trimble measurement tools. The necessary data such as measurement data obtained from the use of GPS equipment or can use data Geodetic RINEX (Receiver Independent Exchange Format) [9].

\section{RESULTS AND DISCUSSION}

In accordance with Indonesian National Standard (SNI) on Horizontal Control Network [10], before the survey for net procurement control point, there are two important jobs that need to be done, namely rekonaisans (field assessment) and benchmarking. Rekonaisans job means to find the best location for the placement of control points in the field and collect the relevant information needed later to benchmarking process and measurement / observation. Benchmarking process intended to make the benchmark (monument) that represent the control points in the field. At measurement locations, the location of the control points are set in front of the Space Administration (point 1) and in front of the toolman room (point 2).

Once the location of a point in the field is determined, then the benchmarking process implemented. In this stage, there are some things that need to be specified:

1. Every monument at any point must be equipped with metal and marble tablet which is mounted on a concrete monument;

2. Monument made from concrete with mixture of cement, sand and gravel (1:2:3), in accordance with the specified design and size (Figure 5);

3. To distinguish the types of monuments from each order of control point network and for the archiving system, the control points must be numbered based on a standardized system. Point numbers must reflect the network orderas well as the location (provincial and district) of the point;

4. Each monument constructed must be made a field sketch and description. Photos of the four directions (north, east, south, and west) should also be made so it can obtain the location of the background picture of every direction. 


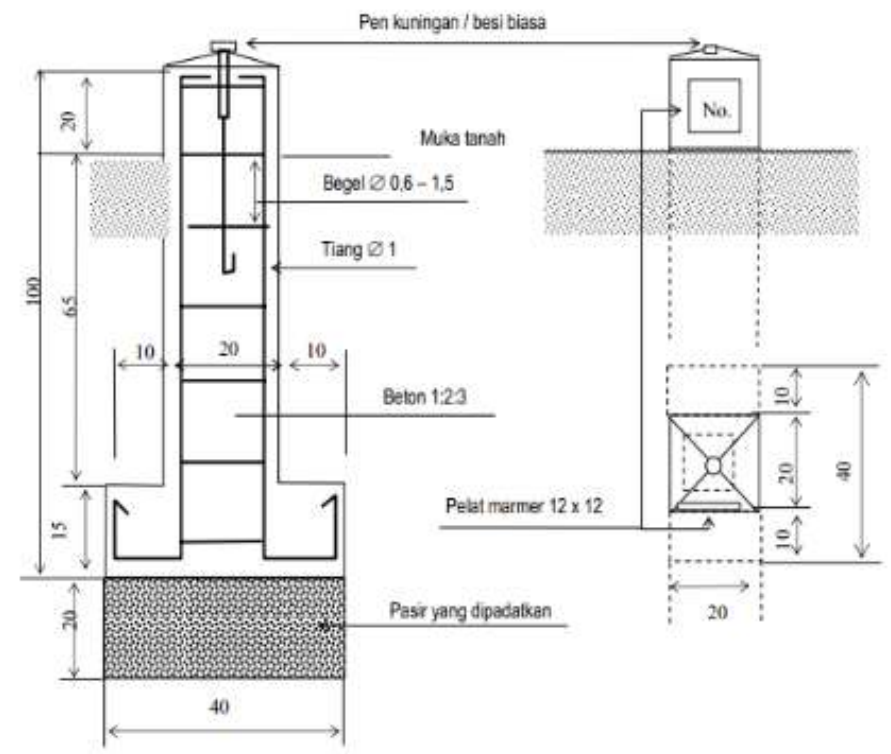

FIGURE 5. Design of the benchmark

After making a benchmark, the next step is measuring geodetic GPS (collecting data). In the data collection field with a static method, it is divided into several stages, among others: 1) create jobs and setting up a new job, 2) setting the base 1 and base 2, data retrieval, data download.

Measurements are conducted geodetic GPS measurements with static method. The equipment used is the GPS Hemisphere S230. Measurements carried out from 09.00 pm until $17.00 \mathrm{pm}$, assisted by student of geomatics program from SMK 1 Kedungwuni. The measurement required more than 2 hour. During data collection, there occurred various obstacles such as sudden death GPS, the battery did not quite reach 2 hours then the measurement is restarted from the basic setting. During this period, the measurement data obtained for each point (more than 2 hours) was 3 hours 45 minutes 50 seconds (point 1 ) and 3 hours 05 minutes 50 seconds (point 2)

For the procurement of the control point network order-00 up to the oder- $4^{\text {th }}$, the technical specifications for data processing methods and strategies are:

1. All GPS observations data are converted into RINEX (Receiver independent exchange format);

2. For processing GPS baselines, the software that is used should be tailored to the GPS receiver used;

3. In GPS baseline processing, the coordinates of the reference point used for determining the baseline vector should not be derived from the absolute positioning result;

4. GPS survey data processing for network procurement order-1 to order-4 (GPS), the software for smoothing nets (free and bound) can be different with software used for baseline processing;

Geodetic GPS is a GPS that has the ability to capture signals L1, L2, or GNSS. Geodetic GPS has the ability to record RAW DATA, which generally have RINEX format. This GPS has a higher accuracy than GPS Navigation, even a millimeter of accuracy.

Since the results of the static methods obtain raw data then prior to use it should be converted. The conversion process of the extension. BIN file extension to .150 and $.15 \mathrm{n}$ require additional devices are RINEX - Desktop. The conversion process is done by downloading from memorycard mounted on the receiver first, then will do the conversion of data from observations in the format (.BIN) into navigation format (15.n) and observation (15.o) using RINEX Dekstop. If the data can not be converted then there should be remeasured. 


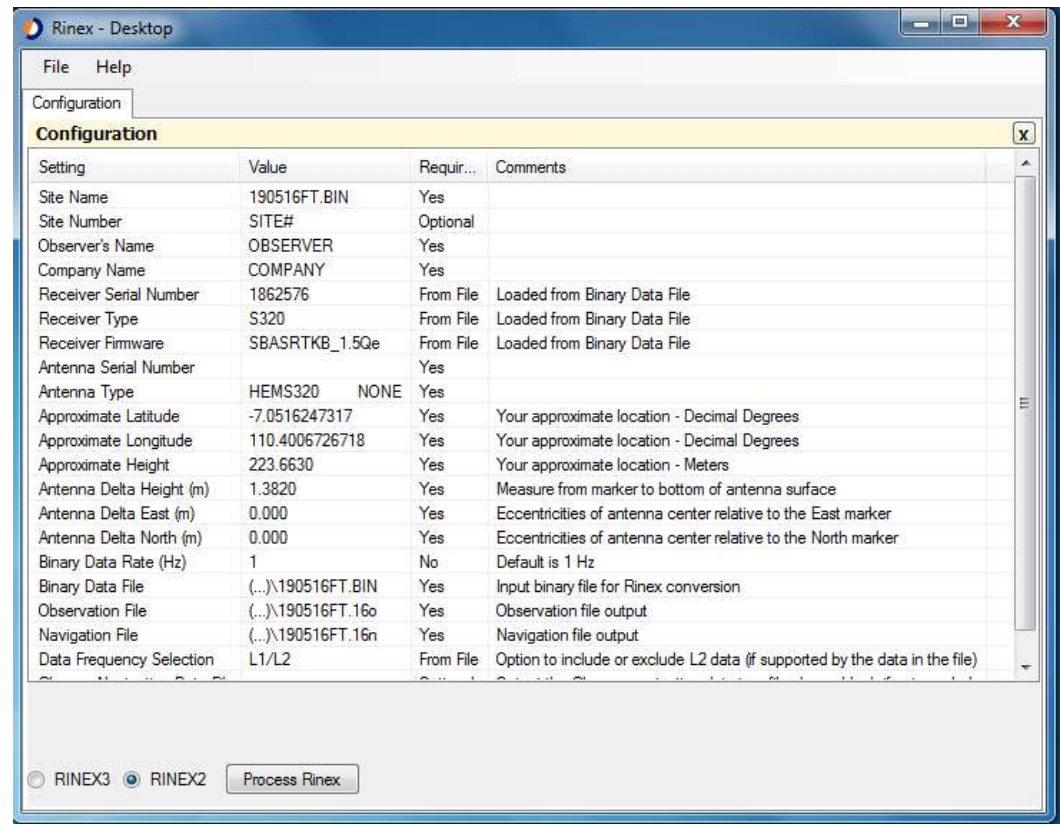

FIGURE 6.Results of RINEX Desktop software

In geodetic GPS measurements using static methods, there are some supporting software for measurement data processing. To obtain good measurement results it is necessary rigor in data collection and data processing time. Here are some applications that are used for data processing static measurement results: TTC (Trimble Total Control), tuberculosis (Trimble Bussines Center), Topcon Tools, and GAMMIT. But in this study, the data processing using a TBC (Trimble Bussines Center), which is in line with geodetic GPS is used.

TBC (Trimble Bussines Center) is a software / software to process the data post-processing, network analysis and grading issued by one firm Trimble measurement tool [8]. The data such as measurement data was obtained from the use of GPS Geodetic equipment or from conversion using RINEX (Receiver Independent Exchange Format) [9].

The main data of the analysis used data from the Pekalongan station (CPKL). After setting the map projections, other settings that can be generated is the geodetic coordinates and UTM coordinates with high accuracy shown in the following table.

TABLE 2. Analysis by Trimble Bussiness Center (TBC)

\begin{tabular}{lccccc}
\hline \multirow{2}{*}{ Observation } & \multirow{2}{*}{ from } & \multirow{2}{*}{ to } & \multirow{2}{*}{ Solution Type } & \multicolumn{2}{c}{ Precision } \\
\cline { 5 - 6 } & & & fixed & 0,005 & 0,023 \\
PKL - SMK (B2) & PKL & SMK & Meters) & V. (Meters) \\
PKL - GMT (B3) & PKL & GMT & fixed & 0,005 & 0,022 \\
SMK - GMT (B1) & SMK & GMT & fixed & 0,002 & 0,003 \\
\hline
\end{tabular}

From the results of these calculations can be stated that the location of geodetic control points in SMKN 1 Kedungwuni Pekalongan are the geographical coordinates (DGN95 / WGS1984) to point 1 is $6^{\circ} 57^{\prime} 33.59086$ "LS; $109^{\circ} 38^{\prime} 37.87710$ "BT; high (ellipsoid) $36235 \mathrm{~m}$ and point 2 is $6^{\circ} 57^{\prime} 31.9220$ "LS; $^{\prime} 109^{\circ} 38^{\prime}$ '32.25194 "BT; high (ellipsoid) $34320 \mathrm{~m}$. As for the UTM coordinates (WGS1984 / Zone49s) to point 1 is $\mathrm{X}=350185,763$ meters; Y= 9230532.116 meters; $Z=12859$ meter and point 2 is $X=350012,969$ meters; $Y=9230582.878$ meters; $Z=10949$ meters. 


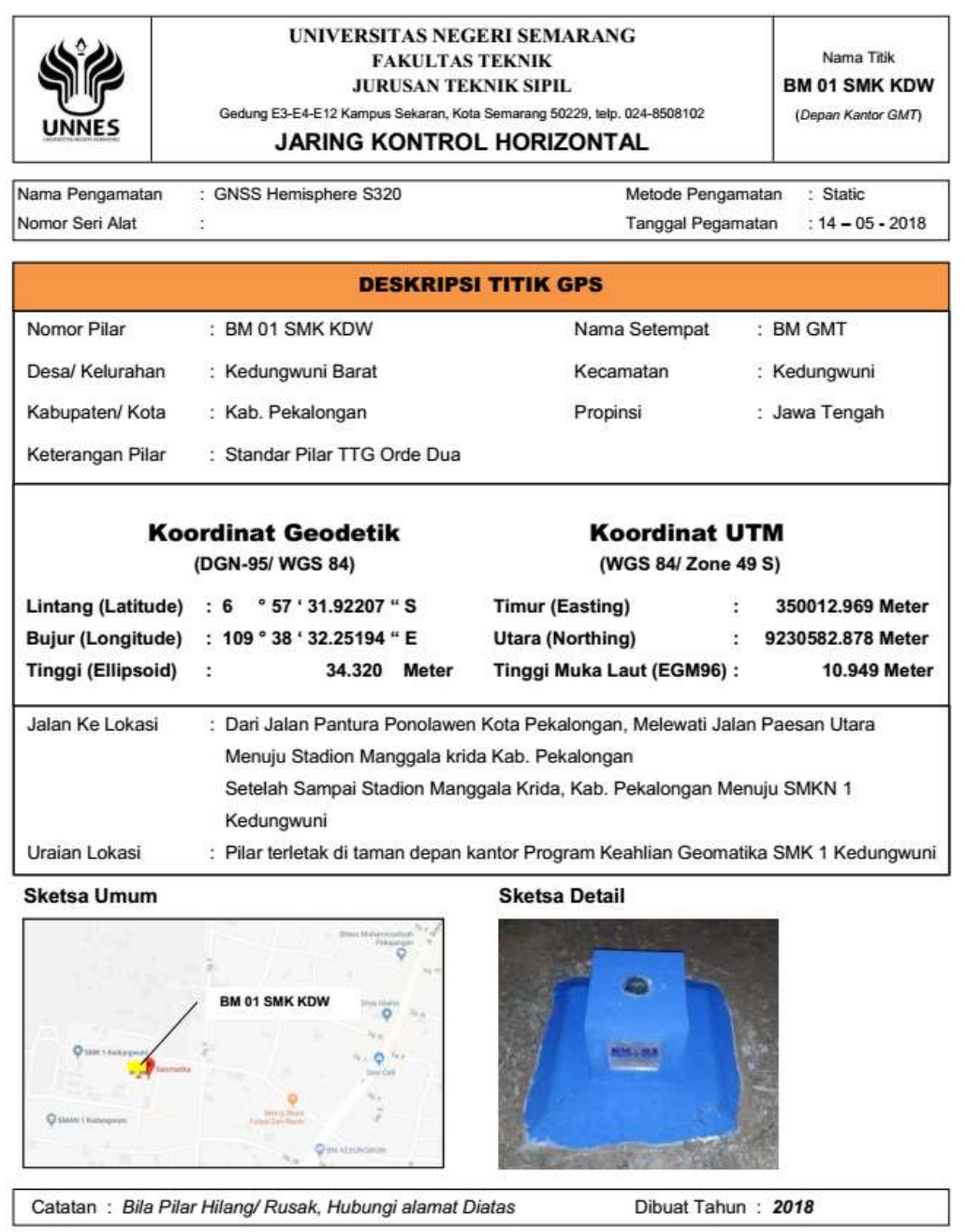

FIGURE 7.Certificate of horizontal control network

\section{CONCLUSION}

One method of geodetic GPS measurements that can be used is a static method. Static positioning method is the positioning of the points are static. Positioning can be performed in absolute or differential, using data pseudorange and phase. The main equipment used in measuring the static method are the base and rover receivers, UHF radio antenna, battery, controller, tribrach, the tripod, pole mount and GPS Cradle, and meter.

Implementation of measurement with static method begins with the adjustment tool until ready for use and continued with the switch on the appliance. Next create new jobs and configure the receiver in accordance with the provisions expected. When these stages have been carried out, then the next is the survey positioning. The last is the displacement stages of field measurement data from the GPS receiver to the software.

Data processing stages, before performing data processing by using the first application data must be converted using RINEX Desktop. After that do the processing of the data using the Business Center Trimble. The final results are expected from static measurements abscissa and ordinate coordinate data with a very high accuracy. From the results of this measurement data obtained geographic coordinates (DGN95 / WGS1984) to point 1 is $6^{\circ} 57^{\prime} 33.59086$ "LS; $109^{\circ} 38^{\prime}$ ' 37.87710 "BT; high (ellipsoid) $36235 \mathrm{~m}$ and point 2 is $6^{\circ} 57^{\prime}$ '31.92207 "LS; $109^{\circ} 38^{\prime} 32.25194$ "BT; high (ellipsoid) $34320 \mathrm{~m}$. As for the UTM coordinates (WGS1984 / Zone49s) to point 1 is $\mathrm{X}=350185,763$ meters; $\mathrm{Y}=9230532.116$ meters; $\mathrm{Z}=12859$ meter and point 2 is $\mathrm{X}=350012,969$ meters; $\mathrm{Y}=9230582.878$ meters; $\mathrm{Z}=10$ 949 meters. 


\section{REFERENCES}

[1] Law of the Republic of Indonesia Number 4 of 2011 on Geospatial Information.

[2] Shanlong Kuang, Geodetic Network Analysis and Optimal Design Concepts and Applications, Ann Arbor Press. Inc: Michigan, 1996.

[3] H.Z. Abidin, Penentuam Posisi Dengam GPS dan Aplikasinya, Pradnya Paramita: Jakarta, 2007.

[4] Indonesian Government Regulation No. 24 of 1997 on Land Registration

[5] Unoosa. 10 Years of Achievement of the United Nations on the Global Navigation Satellite System. New York, 2011 .

[6] H.Z. Abidin, A. Jones, J. Kahar, Survey dengen GPS. PT. Pradnya Pramita, Jakarta, 2011.

[7] Hemisphere. User Guide S320 GNSS Survey Receiver. Arizona: Hemisphere GNSS Inc. 2014.

[8] Trimble. Real-Time Kinematic Surveying Training Guide. California: Trimble Navigation Limited. 2003.

[9] Carson, Carson SurvCE: Uses Manual. Carson Software, 2010.

[10] Indonesian National Standard. SNI 19-6724-2002. Horizontal control Network. 2002. 